\title{
Reflexos da operação lava jato no âmbito dos trabalhos desenvolvidos pela auditoria externa no Brasil*
}

\author{
Impactos de la Operación Lava Jato en el ámbito de los trabajos desarrollados por la auditoría externa en Brasil \\ Impacts of the Operation Lava Jato in the Field of Work Carried out by the External Audit in Brazil
}

\author{
André Luis Rocha de Souza ${ }^{\text {a }}$ \\ Instituto Federal de Educação, Ciência e Tecnologia da \\ Babia, Brasil \\ andresouza@ifba.edu.br \\ ORCID: http://orcid.org/0000-0003-2172-5513 \\ Juliano Almeida de Faria \\ Universidade Federal de Sergipe - UFS, Brasil \\ ORCID: http://orcid.org/0000-0002-0143-9790
}

Recepção: 31/12/2018

Aprovação: 11/10/2019

DOI: https://doi.org/10.11144/Javeriana.cc21.rolj

\section{Resumo:}

A pesquisa objetivou analisar que reflexos a Operação Lava Jato -OLJ-pode gerar sobre os trabalhos desenvolvidos pela auditoria externa e suas normas no Brasil e quais os termos associados à OLJ mais presentes nos relatórios contábeis e pareceres de auditoria da Petrobras. Realizou-se uma pesquisa de natureza bibliográfica e documental, com uma abordagem qualitativa, teórico-empírica e descritiva. Os dados, referentes ao período de 2012 a 2017, foram analisados com apoio do software Nvivo $^{\circledR}$ e extraídos dos seguintes relatórios da Petrobras: Demonstrações Financeiras Padronizadas -DFPs-, Formulários de Referência e Pareceres de Auditoria. Observou-se que os principais reflexos da OLJ sobre os trabalhos da auditoria externa e sobre as Normas Brasileiras de Contabilidade Técnicas de Auditoria Independente são da necessidade de mudanças tanto de natureza técnica e procedimental quanto de natureza legal e normativa. Por fim, a pesquisa evidenciou que o termo com a maior concentração nas DFPs foi o termo Cartel.

Código JEL: M40, M42

Palavras-chave: auditoria, auditoria externa, Operação Lava Jato, governança corporativa, fraudes.

\section{Resumen:}

La investigación tuvo como objetivo analizar qué impactos puede generar la Operación Lava Jato -OLJ- sobre los trabajos desarrollados por la auditoría externa y sus normas en Brasil y cuáles son los términos asociados a la OLJ más presentes en los informes contables y los dictámenes de auditoría de Petrobras. Se realizó una investigación de naturaleza bibliográfica y documental, con un enfoque cualitativo, teórico-empírico y descriptivo. Los datos, referentes al periodo de 2012 a 2017, se analizaron con el apoyo del software $\mathrm{Nvivo}^{\circledR}$ y se extrajeron de los siguientes informes de Petrobras: Estados financieros Estandarizados -EFE- Formularios de Referencia y Dictámenes de Auditoría. Se observó que los principales impactos de la OLJ sobre los trabajos de auditoría externa y sobre las Normas Técnicas Contables Brasileñas para Auditoría Independiente son referentes a la necesidad de cambios de naturaleza tanto técnica y procedimental, como legal y normativa. Finalmente, la investigación mostró que Cartel fue el término con la concentración más alta en los EFE.

Código JEL: M40, M42

Palabras clave: auditoría, auditoria externa, operación Lava Jato, gobierno corporativo, fraude.

\section{Abstract:}

The aim of this research is to analyze the impacts that the Operation Lava Jato -OLJ- may produce on the work carried out by the external audit and its standards in Brazil and which terms associated with the OLJ are most present in the accounting reports and audit opinions from Petrobras. A research of bibliographic and documentary nature was carried out, with a qualitative, theoreticalempirical and descriptive approach. The data, referring to the period from 2012 to 2017, were analyzed with the support of Nvivo ${ }^{\circledR}$ software and were extracted from the following Petrobras reports: Standardized Financial Statements -SFE-, Reference Forms and Audit Opinions. It was observed that the main impacts of the OLJ on the external audit and on the Brazilian Accounting

\section{Autor notes}

a Autor para correspondência. Correio eletrônico: andresouza@ifba.edu.br 
Technical Standards for Independent Audit are related to the need for changes of technical and procedural, as well as legal and regulatory nature. Finally, the research showed that Cartel was the term with the highest concentration in SFS.

JEL Codes: M40, M42

Keywords: auditing, external audit, Lava Jato Operation, corporate governance, fraud.

\section{INTRODUÇÃO}

No período entre 2004 e 2019, a sociedade global tem assistido a um conjunto de escândalos no mundo corporativo e político, emanados de práticas de gestão equivocadas e tendenciosas, voltadas para atender aos interesses particulares em detrimento do interesse corporativo, gerando decisões conflituosas. No início dos anos 2000, nos Estados Unidos da América -EUA-, quando a Enron sucumbiu em face das práticas fraudulentas e, com ela, uma das maiores empresas de auditoria da época, a Arthur Andersen (Biscalquim \& Vieira, 2015), o advento da Lei Sarbaney Oxley (2002) protagonizou o que seria a redução dos escândalos corporativos e, consequentemente, a um conjunto de iniciativas voltadas para mitigar os conflitos de interesses existentes nas decisões de gestão corporativas e assegurar a proteção do patrimônio corporativo das organizações, mediante instrumentos de auditoria consistentes, visando tornar as práticas de gestão mais transparentes e os controles mais eficazes, através de práticas de governança corporativa e de um conjunto de sistemas (Lima, Souza, Facheti, Anjos \& Francchin, 2016), com vistas a reduzir a percepção de riscos dos investidores.

No Brasil, um conjunto de escândalos corporativos e políticos, em particular, entre 2004 e 2019, têm estado em evidência, envolvendo empresas (privadas e públicas), com a participação de empresários, executivos, políticos, além de agentes públicos e da sociedade civil. Segundo Lima et al. (2016), tais escândalos envolvem práticas ilícitas e de fraudes, sejam por meio de relatórios contábeis e financeiros, sejam por meio de processos licitatórios, com reflexos profundos nos processos de negociações.

Ainda nesse sentido, por meio de um processo iniciado em 2009, com a investigação de crimes de lavagem de recursos relacionados ao ex-deputado federal José Janene, em Londrina, no Paraná a deflagração da primeira fase ostensiva da Operação Lava Jato -OLJ- em 2014 e a identificação de um conjunto de empresas envolvidas em escândalos de corrupção, lavagem de dinheiro, fraudes financeiras e patrimoniais, dentre outras crimes (Brasil, 2017a), verifica-se que, mesmo com o avanço dos modelos de governança corporativa, melhoria e avanços dos processos regulatórios e sistemas de controles avançados, as práticas corporativas ilícitas ainda continuam sendo reinventadas e burlando os controles internos das empresas. Esses fatos vêm impactando fortemente a confiança dos mercados, em particular os mercados em ascensão (Lima et al., 2016) com reflexos negativos para as empresas - seja do ponto de vista econômico e financeiro, seja do ponto de vista reputacional e de legitimidade, como também para a sociedade de um modo geral.

No âmbito do mercado financeiro, esse contexto provoca desconfiança nos stakeholders, sobretudo nos investidores que possuem recursos alocados nas empresas, uma vez que estes esperam que seus investimentos sejam corretamente aplicados e gerenciados pelas investidas, visando à proteção dos ativos.

Transcorrido quase duas décadas do surgimento da Lei Sarbaney Oxley, acompanhada por um conjunto de outras normas nacionais e internacionais de contabilidade e de auditoria, as práticas de fraudes ainda continuam ocorrendo, aumentando os desafios da contabilidade e de suas técnicas e instrumentos de controle, em particular, a auditoria (Agoglia, Beaudoin \& Tsakumis, 2009).

Em face do exposto, observa-se a necessidade refletir sobre as práticas de auditoria no contexto atual no sentido de buscar mecanismos que melhorem o planejamento, as estratégias e os procedimentos que contribuam na redução dos riscos dos trabalhos dos auditores, na redução da percepção de risco dos investidores e assegurar, de forma fidedigna, as informações divulgadas pelas organizações aos mercados, além 
de mitigar os riscos da ocorrência de fraudes nessas corporações (Bierstaker, Brody \& Pacini, 2006; Carneiro, Szuster, Siqueira \& Fonseca, 2017).

O surgimento da técnica contábil de auditoria está relacionado com a globalização econômica e expansão dos mercados financeiros, bem como, com o crescimento das empresas que passaram a ocupar outros espaços econômicos e geográficos, através da criação de filiais e novos negócios em outros países, induzindo, portanto, a criação de normas e mecanismos de controle dos fluxos de recursos negociados (Lélis, 2010). Quanto à técnica de auditoria, pode ser compreendida sob duas dimensões: a interna e a externa. Segundo Rossi, Silva \& Lopes (2016), enquanto a auditoria interna analisa a estrutura operacional dos controles internos, a auditoria externa, além de utilizar os controles internos das empresas auditadas, busca verificar a fidedignidade das informações evidenciadas nas demonstrações contábeis através da análise de documentos que comprovem tais divulgações.

Diante do exposto, os desafios trazidos para a contabilidade em nível global, e, em particular, no âmbito do Brasil, constituem-se de um conjunto de questionamentos sobre o papel e a abrangência da auditoria e os controles internos corporativos, pois um conjunto de práticas ilícitas têm estado em evidências, a partir de operações realizadas pela Polícia Federal e o Ministério Público Federal -MPF- no âmbito da OLJ. Dentre as companhias envolvidas nestas operações, destaca-se a Petrobras, uma das principais estatais brasileira, com operação global no setor de energia, atuando na exploração, produção e refino, além de comercialização de petróleo e seus derivados, na qual foram verificados desvios significativos de bilhões de reais (Vilela, Grossi, Carvalho \& Ribeiro, 2018; Brasil, 2017a), apesar de ser submetida à auditorias externas e apresentar estruturas de governança corporativa e controles internos implementados. No bojo dessa discussão, cabe destacar um dos maiores desafios da contabilidade no contexto atual que é o controle da influência política, a qual tem tido papel direto nos escândalos envolvendo empresas no Brasil.

Nesse contexto, cumpre destacar que dentre as responsabilidades dos profissionais da auditoria independente estão analisar as informações contábeis e operacionais, avaliar o processo de governança e gestão de risco, o que requer desses profissionais um conjunto de conhecimentos, técnicas e habilidades, conforme destacam Dordevic e Dukic (2015). Já no que se refere aos agentes responsáveis pela auditoria interna estão às responsabilidades de analisar as informaçóes divulgadas pela contabilidade, o monitoramento do controle interno, contribuindo para que as informações evidenciadas pelas companhias sejam fidedignas e estejam em linhas com a política contábil da empresa.

Assim, dado a relevância da auditoria para a integridade patrimonial das organizações e considerando o papel da contabilidade de controlar o patrimônio corporativo de forma eficiente e efetiva, questiona-se: Que reflexos a Operação Lava Jato -OLJ- pode gerar sobre os trabalhos desenvolvidos pela auditoria externa e suas normas no Brasil e quais os termos associados à OLJ mais presentes nos relatórios contábeis e pareceres de auditoria da Petrobras?

Sendo assim, o objetivo geral da presente pesquisa consistiu em analisar que reflexos a OLJ pode gerar sobre os trabalhos desenvolvidos pela auditoria externa e suas normas no Brasil e quais os termos associados à OLJ mais presentes nos relatórios contábeis e pareceres de auditoria da Petrobras.

Destaca-se, portanto, a importância em aprofundar as discussões sobre o papel da auditoria na prevenção de fraudes e práticas ilícitas na gestão corporativa. Nesse sentido, do ponto de vista teórico, a pesquisa contribui no sentido de refletir acerca das reconfigurações necessárias ao papel da auditoria. Sob o prisma prático, apresenta um conjunto de informações que podem subsidiar os profissionais da área com reflexões importantes na construção de estratégias para melhorar os trabalhos dos auditores.

Assim, observa-se que, a partir dos termos identificados nos relatórios, podem-se avaliar os mecanismos mais frequentemente (relatórios e termos) lançados mão pela Petrobrás e os auditores independentes para fazer jus à comunicação dos reflexos da OLJ em suas operações no período de estudo. Com isso, profissionais podem ser beneficiados, visto que, caso já não o tenham feito, contarão com maior esclarecimento acerca dos reflexos da OLJ na Petrobrás. Para professores e estudantes interessados, os benefícios deste trabalho podem 
impactar positivamente no ensino e pesquisa acadêmica, porquanto contarão com termos direcionadores a partir dos quais poderão aprofundar pesquisas sobre o tema, estudar estratégias de comunicação e avaliar reflexos da OLJ na Petrobras.

Por fim, os demais usuários das informações contarão com um conjunto de itens os quais demonstram uma referência da estratégia de apresentação da Petrobrás quanto à evidenciação dos reflexos da OLJ em suas operações no período em estudo. Pressupõe-se que, quanto maior o volume de informação e esclarecimento, mais o mercado estará capacitado para incluir tais informações em seus modelos decisórios.

\section{REVISÃO DA LITERATURA}

\section{A teoria dos stakeholders e governança corporativa}

Com o advento da globalização e com a expansão dos mercados, as organizações têm passado por constantes transformações. Essas transformações têm exigido da contabilidade um conjunto de avanços nos procedimentos e técnicas que acompanhem as mudanças corporativas e regulatórias, bem como que ofereça asseguração das informações contábeis utilizadas na tomada de decisão do gestor (Mendes \& Martins, 2014; Biscalquim \& Vieira, 2015).

Esse processo é marcado, também, pela expansão dos papéis e objetivos corporativos que ampliou os grupos de interesses aos quais se faz necessária a prestação de contas das atividades organizacionais. Esse grupo de interesse, antes focado apenas nos acionistas, expandiu-se para um conjunto de pessoas que direta ou indiretamente relaciona-se com as organizações, a partir de objetivos distintos, a exemplo de credores, fornecedores, governos, dentre outros, denominados de stakeholders (Freeman, 2010). Em particular, com o avanço das discussões acerca das práticas de governança corporativa, as organizações passaram a se depararem com a necessidade internalizar questões externas relacionadas às partes interessadas (Lélis, 2010). Essa ampliação de papéis e objetivos das corporações está no âmbito dos estudos desenvolvidos a partir da Teoria dos Stakeholders (Freeman, 2010; Clarkson, 1995; Donaldson \& Preston, 1995), da Teoria da Evidenciação e da Legitimidade (Dias Filho, 2012; Souza, Cruz, Machado \& Mendes, 2008; Piacentini, 2004; Hybels, 1995).

Para Freeman e Reed (1983) e Freeman (2010), a gestão das organizações deve considerar, em suas decisões, o conjunto de grupos de interesses e não apenas os interesses restritos dos acionistas, que são focados na maximização dos resultados e valor dos investimentos. Segundo os autores, compóem esses grupos de interessados agentes como os governos credores, empregados, clientes, comunidade, dentre outros, além dos acionistas das empresas.

O avanço dos mercados e a expansão exponencial das organizações fez com que as pressões advindas desses grupos aumentassem, segundo Parmar, Freeman, Harrison, Purnell \& De Colle (2010) e Buosi (2014), demandando a necessidade de uma reflexão acerca dos conflitos gerados no processo decisório corporativo.

Nesse contexto, destaca-se que o atendimento aos interesses dos stakeholders deve ser acompanhada por práticas de gestão compatíveis com os objetivos corporativos e em linhas com as boas práticas de governança corporativa além de um importante papel do governo e das demais associações de interesse com o intuito de proteger o bem comum da sociedade por meio da criação de leis e mecanismos de combate à fraude (De Almeida, Vieira Neto, Abunahman \& Nascimento, 2017).

Dessa forma, a auditoria, como técnica de asseguração das informações organizacionais evidenciadas pela gestão, tem papel fundamental no fortalecimento da governança corporativa e na redução da percepção dos riscos corporativos para o mercado, sobretudo no papel de garantir que as informações divulgadas sejam fidedignas (Almeida, 2017). 


\section{A Operação Lava Jato -OLJ-e as práticas de auditoria externa no Brasil}

Observa-se que a auditoria é essencial para as organizações assegurarem o seu patrimônio. A auditoria contribui para que os stakeholders -interessados diretamente ou indiretamente nos resultados empresariaisconfiem nos controles internos e nos resultados corporativos alcançados e divulgados (Rossi et al., 2016).

Contudo, os desafios nesse processo ocorrem, principalmente, a partir dos controles internos que, apesar de serem independentes em relação às áreas, estão vinculados à hierarquia maior de uma corporação e tem como objetivo eliminar possibilidades de ocorrência de erros e fraudes com vistas à proteção dos ativos (Rossi et al., 2016). Por outro lado, apesar dos seus objetivos, nem sempre os controles internos são eficientes e eficazes, em função das influências políticas que podem comprometer toda uma estrutura de governança, a exemplo das práticas ilícitas que ocorreram na Petrobras, Eletrobras, dentre outras companhias, nas quais há indicações políticas para cargos executivos e que decidem sobre o futuro dessas organizações, conforme sinalizou Pereira e Souza (2017) em sua pesquisa.

Sendo assim, se faz necessária uma reflexão do papel da auditoria no contexto recente de conjunto de práticas ilícitas evidenciadas pela OLJ no Brasil e discutir as possíveis estratégias para a redução dos riscos envolvidos nos trabalhos dos auditores requerendo a diversificação dos métodos e procedimentos de trabalho, a exemplo da utilização de servidos de contadores forenses, uso de software de análise, mineração de dados, dentre outras estratégias (Bierstaker et al., 2006; Carneiro et al., 2017; Nascimento, Santos, Santiago, Araújo, Lima \& Maciel, 2018).

A auditoria, a partir de uma visão ampla, pode ser compreendida como um conjunto de técnicas e procedimentos que visam certificar a veracidade e grau de confiabilidade das informações financeiras divulgadas pelas empresas aos diferentes stakeholders, através das demonstrações contábeis. A partir das técnicas e procedimentos de auditoria é possível verificar se as demonstrações financeiras das organizações refletem, com fidedignidade, a realidade corporativa (Stuart, 2014).

A realização da auditoria externa nas empresas, geralmente, decorre da exigência da legislação, demandas de investidores, acionistas, órgãos de controle e fiscalização, dentre outros, cujos interesses e objetivos são distintos. A conformidade ou não conformidade das informações financeiras verificadas são evidenciadas através de um parecer de auditoria, composto por um conjunto de informações acerca do objeto estudado, fundamentada em normas e procedimentos de contabilidade e auditoria vigentes, nacionais e internacionais (Almeida, 2017).

Destacam-se, nas atividades dos auditores externos, os trabalhos de asseguração, cujo objetivo é garantir a confiabilidade das informações e dos dados divulgados (avaliando-se para tanto os critérios adotados e os objetos), além dos controles internos, reduzindo assim os riscos dos trabalhos destes profissionais, bem como, a percepção de risco dos usuários das demonstrações financeiras (CFC, 2012; Freitas \& Cruz, 2016).

Os trabalhos de asseguração, executados por auditores externos, conforme o CFC (2012), através da Resolução CFC No 1.202/2009, pode ser classificados em de duas formas: (i) asseguração razoável; ou (ii) asseguração limitada. Em relação à asseguração razoável (i), ela consiste no trabalho de auditoria com o objetivo de verificar a fidedignidade das informações divulgadas nas demonstrações financeiras, através da qual é possível reduzir os riscos ao mínimo possível dos trabalhos dos auditores... "considerando as circunstâncias $^{1}$ do trabalho como base para uma forma positiva de expressão da conclusão do auditor independente" (CFC, 2012, p. 9). Quanto à asseguração limitada os auditores devem buscar a redução dos riscos dos trabalhos a um nível aceitável. Assim, segundo o CFC a asseguração limitada é empregada na condição em que "o risco seja maior do que no trabalho de asseguração razoável, como base para uma forma negativa de expressão da conclusão do auditor independente” (CFC, 2012, p. 9).

Apesar das normas definirem procedimentos e estratégias para assegurar informações divulgadas de forma fidedignas pelas corporações, verifica-se que os meios e as formas de práticas de fraudes vêm sendo reinventadas pelos os agentes que as praticam, o que requer, cada vez mais, estratégias robustas dos auditores. 
A pesquisa de Rossi et al. (2016) objetivou analisar a ocorrência de fraudes em Empresas de Rodovias (concessionárias). Os resultados evidenciaram que as principais possibilidades de fraudes nesse segmento são os desvios de recursos recebidos dos usuários do pedágio e desvios de recursos em processo de expansão e/ou manutenção das rodovias. Além disso, verificou-se a não existência de um departamento de auditoria interna na organização.

Para Dordevic e Dukic (2015), embora não se possa garantir que as estruturas de governança sejam suficientes para evitar riscos de fraudes, compete à auditoria interna o papel fundamental na prevenção e mitigação desses riscos nas organizações. Ademais, os autores destacam que a eficácia dos sistemas de controle interno não se resume apenas a existência de normas e manuais de procedimentos internos, mas do apoio que recebe da organização, além das habilidades e conhecimentos inerentes aos auditores.

Conforme definem Freitas e Cruz (2016), fraudes podem ser conceituadas como um conjunto de práticas, ilícitas, intencionais, com objetivos de atender a interesses pessoais e/ou particulares de determinadas pessoas e envolvem alteraçóes intencionais de registros e documentos, modificando a realidade corporativa, desvio de recursos da empresa e exclusão e/ou omissão de fatos e informações relevantes das demonstrações financeiras. Já o erro, trata-se de atos que podem provocar mudanças nas informações divulgadas, mas que não foram praticadas com intenção ilícita, podendo ser retificado.

Destaca o CFC (2012) que as fraudes podem ocorrer de duas formas: a primeira relacionada com a manipulação de dados, e a segunda relacionada com a apoderação indevida de ativos da corporação. Dessa forma, compreende que "envolve dolo para obtenção de vantagem injusta ou ilegal... de um ou mais indivíduos da administração, dos responsáveis pela governança, empregados ou terceiros (CFC, 2012, pp. 97, 105). Para Dordevic e Dukic (2015), a fraude gera consequências substanciais sobre a performance econômico-financeira das organizações, bem como sobre sua imagem e legitimidade perante o mercado.

Segundo o CFC (2012), é de responsabilidade das estruturas de governança e de gestão zelar pelo cumprimento de normas e procedimentos que assegurem a integridade do patrimônio corporativo, através de ações que identifiquem riscos de fraudes, bem como evitem a sua ocorrência. Assim, a responsabilidade pela detecção dessas práticas é da estrutura de governança e da gestão e não da auditoria em si, embora esteja no contexto do trabalho do auditor. Para tanto, a corporação, por meio da sua estrutura de governança, deve desenvolver e implementar iniciativas internas, tais como: códigos de condutas, disseminação de comportamentos éticos, dentre outras, buscando conscientizar os funcionários e gestores quanto à necessidade de atitudes e práticas.

Diante do exposto, não compete ao auditor a responsabilidade exclusiva pela detecção das fraudes, mas verificar se as informações divulgadas pelas corporações refletem a realidade corporativa. Por outro lado, o CFC (2012) destaca que:

O auditor que realiza auditoria de acordo com as normas de auditoria é responsável por obter segurança razoável de que as demonstrações contábeis, como um todo, não contêm distorções relevantes, causadas por fraude ou erro (grifo nosso). Conforme descrito na NBC TA 200, devido às limitações inerentes da auditoria, há um risco inevitável de que algumas distorçôes relevantes das demonstrações contábeis podem não ser detectadas, apesar de a auditoria ser devidamente planejada e realizada de acordo com as normas de auditoria... (grifo nosso). (CFC, 2012, p. 98)

Segundo Freitas e Cruz (2016), embora o auditor não tenha responsabilidade sobre as fraudes, ao identificar possíveis desvios de recursos durante os trabalhos deve comunicar a gestão da corporação sobre tais fatos. A pesquisa realizada pelos autores objetivou avaliar a influência dos riscos de auditoria nos reportes e na emissão do parecer do auditor. Os dados foram coletados a partir dos relatórios de auditoria de empresas Petrobrás, Odebrecht, Camargo e Correa, Andrade Gutierrez, Carioca, Mendes Junior e Eletrobrás, envolvidas na OLJ. Os resultados mostraram que os trabalhos de auditoria foram desenvolvidos nas empresas, observando as normas vigentes, analisando, para tanto, os controles internos e realizando os testes para a redução dos riscos e análise da amplitude da auditoria, cujas informações quanto à OLJ foram destacadas nas notas explicativas, incluindo ressalvas relacionadas a possíveis perdas em decorrência da OLJ. 
A pesquisa de Pereira e Souza (2017) objetivou analisar as práticas de governança corporativa descumpridas pela Petrobras em face da operação lava jato. Os resultados evidenciaram falta de independência do conselho executivo, com forte influência política, em particular, em relação às indicações da composição do conselho. Além disso, verificou-se que a Petrobras possuía canais de denúncia gerenciados internamente, o que não é recomendado pelas boas práticas de governança corporativa, além de fragilidades nos controles internos e divergência, em termos estruturais, entre as práticas adotadas pelas empresas e as recomendadas pelo mercado em relação à governança corporativa.

Já a pesquisa de Vilela et al. (2018) objetivou mensurar os efeitos decorrentes da deflagração da OLJ sobre o valor da Petrobras até o ano de 2016, utilizando a técnica de avaliação econômica de empresa de Fluxo de Caixa Descontado -FCD- com taxas de desconto distintas para três cenários. Os autores verificaram que a OLJ impactou negativamente o valor da companhia. Ademais, segundo os autores, a perda de valor da companhia impacta sua competitividade, pois "perde também a capacidade de atrair investimentos externos, reduzindo seu grau de competitividade no mercado interno e, principalmente, no mercado internacional" (Vilela et al., 2018, p. 24).

Por fim, o trabalho de Schmitz e Rover (2017) comparou o nível de disclosure anticorrupção em uma amostra de empresas do ramo empreiteiro, separando-as em Investigadas (I) ou Não Investigadas (NI) tendo como pano de fundo a OLJ. Para tanto, adotou uma abordagem metodológica qualitativa e quantitativa, cuja amostra foi composta por empreiteiras selecionada pelos autores a partir de um ranking definido na revista $O$ Empreiteiro. Os autores analisaram documentos e instrumentos divulgados pelas empresas relacionadas com enfrentamento à corrupção, tais como diretrizes de combate à corrupção, relatório anual de administração, dentre outros, utilizando instrumentos qualitativos de coleta de dados, associados às diretrizes do Programa de Integridade proposta pela Controladoria Geral da União, com métricas de atribuição de pontuação caso as empresas atendessem às questões de evidenciação e testes estatísticos (teste de Mann-Whitney) para comparar os níveis de disclosure dos grupos de empresas analisados. Os resultados evidenciaram indícios que as empresas do grupo "Investigadas" apresentaram maior nível de evidenciação do que as do grupo "Não Investigadas", reforçando uma tendência pressuposta pelo incentivo ao disclosure feito naquelas que estão envolvidas em escândalos de corrupção.

Na presente pesquisa, a avaliação está restrita à Petrobras, na medida em que atua na empresa fonte dos recursos desviados pelas empreiteiras investigadas.

\section{PROCEDIMENTOS METODOLÓGICOS}

\section{Caracterizações da pesquisa}

A presente pesquisa caracteriza-se como uma pesquisa exploratório, de natureza bibliográfica e documental, cuja abordagem foi qualitativa, teórico-empírica, para a qual foram usadas fontes de dados secundários, através de livros, artigos científicos, relatórios técnicos, normas e leis, bem como acesso a sites institucionais e a bases de dados públicas. Dessa forma, constitui-se em uma pesquisa de natureza descritiva, com uma análise sobre os reflexos da Operação Lava Jato -OLJ- no âmbito dos trabalhos desenvolvidos pela auditoria externa nas organizações, tendo em vista que, mesmo com todo o avanço nas normas de contabilidade nacionais e internacionais, nos últimos anos, as práticas de fraudes e corrupção têm continuado nas organizações, conforme a OLJ evidenciou.

Com o objetivo de levantar e analisar as principais fraudes identificadas pela OLJ nas empresas brasileiras, foram coletados dados em site específico criado pelo MPF para tal fim, através do link: www.lavajato.mpf.mp.br, compreendendo o período de 2014 a 2017. O período foi escolhido por representar a maior atuação da OLJ desde sua criação (a partir de 2014) sendo limitada pela disponibilidade dos dados 
das empresas e encerramento da pesquisa em 2018 com base nos relatórios publicados referentes ao exercício até 2017. Foram utilizados também, como fonte de dados secundários, a fim de verificar os termos associados à OLJ mais presentes, as Demonstrações Financeiras Padronizadas, Formulários de Referência e Pareceres de Auditoria, do período de 2012 a 2017, da Petrobras, empresa na qual a OLJ identificou desvio de bilhões de reais e por ser uma das maiores estatais do país envolvida na operação (Brasil, 2017f). Por fim, figuras contendo cotações das ações da Petrobras foram coletados por meio do Google, a fim de que análise técnica fosse realizada para avaliar o comportamento dos preços em face dos reflexos da OLJ.

\section{Coleta e análise de dados}

O esquema descoberto pela OLJ é bastante complexo e envolve um conjunto de agentes e recursos em todos os setores, com práticas de diferentes crimes evidenciados após as investigações. A tabela 1 sintetiza os principais crimes/práticas ilícitas evidenciados pela OLJ.

TABELA 1

Crimes e Práticas Ilícitas evidenciadas pela Operação Lava Jato - OLJ

\begin{tabular}{|l|}
\hline \multicolumn{1}{|c|}{ Crimes / Práticas ilícitas } \\
\hline Corrupção (ativa e passiva) \\
\hline Crimes contra o sistema financeiro nacional e internacional \\
\hline Tráfico transnacional de drogas \\
\hline Formação de organização criminosa \\
\hline Lavagem de dinheiro e outros ativos \\
\hline Fraudes em licitações \\
\hline Falsidade ideológica \\
\hline Evasão de divisas \\
\hline Cartel (crime contra a ordem econômica) \\
\hline Embaraço a investigação de organização criminosa \\
\hline Tráfico de influência \\
\hline Obstrução de justiça \\
\hline Violação de sigilo funcional \\
\hline
\end{tabular}

Fonte: Brasil (2017e, p. 1).

Com o objetivo de tratar e analisar os dados coletados dos relatórios financeiros e pareceres de auditoria da Petrobras, utilizou-se o Software Nvivo. O Nvivo ${ }^{\circledast}$ é um sistema de análise documental que disponibiliza ferramentas de análise textual proveniente de relatórios, transcrições de áudio, imagens e outros dispositivos de comunicação. Este sistema viabiliza a busca, a seleção, a análise de correlação e armazenamento de trechos dos documentos categorizados por meio de uma ferramenta denominada Nó. Os Nós representam temas, tópicos, conceitos, ideias, opiniões ou experiências identificadas na pesquisa por meio da qual é possível codificar (agrupar) todas as referências desejadas na pesquisa. Sendo assim, para a construção dos Nós no sistema foram utilizados os 13 Crimes, conforme identificados na tabela 1.

Após a inserção dos relatórios no $\mathrm{Nvivo}^{\circledast}$, a consulta foi realizada individualmente tendo os crimes apresentados na tabela 1 como direcionamento. Como resultado intermediário, o $\mathrm{Nvivo}^{\circledR}$ gera para cada consulta um relatório denominado "Árvore de palavras" no qual constam os 5 termos anteriores e 5 posteriores ao termo encontrado no texto de cada uma das fontes (Relatórios anuais) inseridas no sistema. A partir da árvore de palavras, gerada para cada um dos 13 crimes e, por sua vez, gerada em cada um dos relatórios (2014 
a 2017), o sistema viabiliza a consulta individual dos resultados demonstrando, por meio de uma interface, o acesso ao relatório fonte (podendo ser vários relatórios simultaneamente).

A análise documental foi realizada por meio da leitura detalhada de cada trecho encontrado pelo sistema de modo a identificar sua relação com os crimes (Tabela 1) e a OLJ. Esta análise levou em consideração o conteúdo do crime versus o conteúdo do trecho encontrado, eliminando os termos apresentados nos relatórios por meio da seleção automática do Nvivo, mas que, no contexto, não apresentavam qualquer relação com a OLJ. O sistema permite a seleção no relatório fonte daqueles trechos aprovados na leitura detalhada e armazenamento dos trechos aos respectivos Nós (Crime). Assim, foi possível identificar, nos 18 relatórios, a presença e extensão dos crimes e agrupá-los por meio dos Nós criados no sistema. O sistema disponibiliza relatórios com os trechos marcados os quais geram o percentual de cobertura de cada Nó.

O percentual de cobertura (\%Cob) é representação relativa da quantidade de palavras encontradas na soma total dos trechos selecionados tomando como denominador a quantidade total de palavras em cada relatório. Cada trecho selecionado foi analisado em detalhe, quanto a sua relação com a OLJ. Assim, o \%Cob demonstra a quantidade de palavras que evidenciam informações o crime como reflexo da OLJ. Por meio da correlação de Pearson calculada pelo software Nvivo foi possível analisar (entre os Nós) aqueles os quais estão citados em ambientes textuais semelhantes, permitindo entender associações nos quais os termos foram utilizados. Os \% Cob foram ponderados e agrupados por crime, de modo a mensurar a o grau de evidenciação dos mesmos nos documentos analisados a saber: Demonstrações Financeiras Padronizadas, Formulários de Referência e Pareceres de Auditoria, todos do período de 2012 a 2017.

\section{ANÁLISE DA OLJ E SEUS REFLEXOS SOBRE OS TRABALHOS DA AUDITORIA EXTERNA}

A Operação Lava Jato -OLJ-, iniciada em 2014, teve esse nome atribuído devido ao envolvimento de empreendimentos de lava a jato de veículos e postos de combustíveis em transações de fluxos físicos e financeiros ilegais, envolvendo agentes (doleiros) do mercado negro ou como é conhecido o mercado paralelo de câmbio (Brasil, 2017d).

Desde o início da OLJ (2014), em Curitiba, que envolveu operações no mercado paralelo de câmbio, a operação tem se expandido para diferentes regiões, setores e segmentos da sociedade brasileira e em outros países, envolvendo grandes empresas, a exemplo da Petrobras, Odebrecht, JBS, executivos e empresários, servidores e agentes públicos, agentes da sociedade civil e políticos (Brasil, 2017d).

A investigação, que teve início na Petrobras, se expandiu rapidamente em virtude da complexidade e da dimensão do esquema que envolve empresas públicas, empresas privadas e a classe política, sendo que, em 2014, os trabalhos tiveram início na primeira instância e, em 2015, no âmbito da Procuradoria Geral da República (PGR), foi criado uma equipe de trabalho para atuar na operação (Brasil, 2017a). Ainda no ano de 2015, o MPF criou um site específico para divulgar e sistematizar as informações relacionadas com a OLJ (www.lavajato.mpf.mp.br).

Para Pereira e Souza (2017), os passos iniciais da OLJ ocorreram em 2013 com a identificação, a partir de ligações telefônicas capturadas, envolvendo o diretor, à época, da área de abastecimento da Petrobras, Sr. Paulo Costa. Mas o marco inicial da operação ocorreu no primeiro trimestre de 2014, quando foram identificadas estruturas montadas para operar esquemas ilícitos, bem como práticas ilegais na Petrobras, a exemplo de desvio de recursos, além de contratos envolvendo projetos de infraestrutura no país. Essa operação constitui uma das maiores operações de combate a corrupção na América Latina e, em particular, a maior do Brasil (Brasil, 2017a, 2017c; Pereira \& Souza, 2017).

Conforme Vilella et al. (2018), a OLJ provocou impactos sobre o valor da Petrobras. Segundo os autores, entre os anos de 2012 e 2013, os preços médios das ações da companhia estiveram superiores ao valor de 
R\$ 18,00. Já em 2014, quando a Petrobras teve o seu ex-diretor de abastecimento preso (Brasil, 2017f), particularmente a partir de setembro, os preços das ações da Petrobras tanto ordinária (PETR3) quanto preferenciais (PETR4) passaram a apresentar tendência de baixa, conforme figuras 1 e 2, respectivamente, tendo alcançado o valor de $\mathrm{R} \$ 9,87$ (em 26/12/2014) e $\mathrm{R} \$ 6,25(22 / 01 / 2016)$ para as ações ordinárias e o valor de $\mathrm{R} \$ 10,40$ (em 26/12/2014) e R 4,44 (22/01/2016), conforme segue.

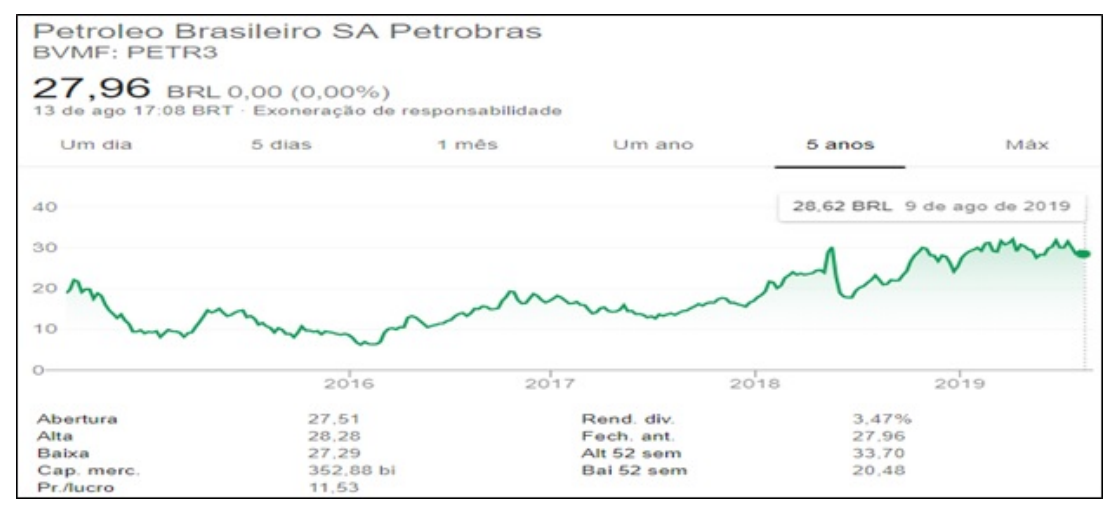

FIGURA 1

Preço da ação PETR3 (ordinária) da Petrobras (histórico de 5 anos) Fonte: Google (2019).

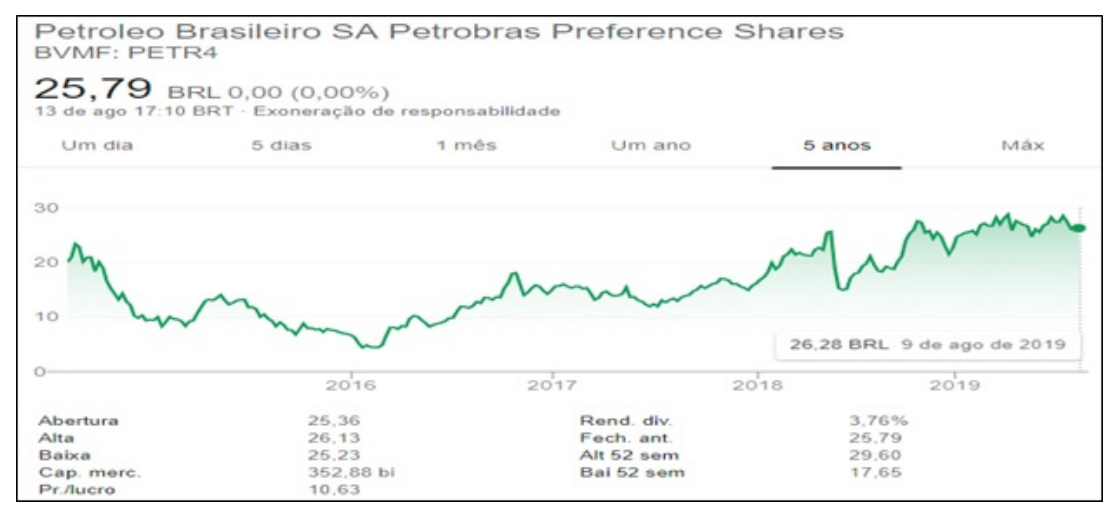

FIGURA 2

Preço da ação PETR4 (preferenciais) da Petrobras (histórico de 5 anos) Fonte: Google (2019).

Os preços das ações podem ser afetados tanto por questões internas, as práticas de gestão e governança corporativa, o desempenho econômico e financeiro da companhia no setor e no mercado global (Souza, Silva Junior, Andrade \& Fernandes, 2018). Além disso, segundo Vilela et al. (2018),

é relevante destacar que, além dos fatores internos relativos à corrupção na Petrobras e ao ambiente político e econômico brasileiro, diversos eventos também contribuíram para elevar o nível de incerteza no mercado internacional, os fluxos de capitais, significativamente voláteis, e o preço das commodities deprimido. (Vilela et al., 2018, p. 15)

A OLJ envolve um conjunto de ações articuladas com outros países, sobretudo no levantamento de documentos, dados, fluxos financeiros decorrentes dos desvios, dentre outras informações. Ao todo, segundo Brasil (2017b; 2017e), a PGR, enviou, aproximadamente, 200 pedidos, envolvendo, aproximadamente, 40 países referentes à OLJ. Da mesma forma, mais de 25 países enviaram, aproximadamente, 140 pedidos à PGR relacionados à operação. Destaca o Brasil (2017b) que:

Desde que a operação teve início no Ministério Público Federal do Paraná, já foram feitas 67 acusações criminais contra 282 pessoas (sem repetição de nomes), sendo que em 34 casos já houve sentença por crimes de corrupção, contra o sistema financeiro, lavagem de dinheiro, formação de quadrilha, entre outros (grifo nosso). Até o momento houve 165 condenações 
contra 107 pessoas. Ao todo, $\mathrm{R} \$ 10,3$ bilhões são alvo de recuperação e $\mathrm{R} \$ 3,2$ bilhões em bens dos réus já foram bloqueados. (Brasil, 2017b, p. 1)

Nesse esquema, os papéis dos atores envolvidos eram bem definidos e podem ser observados a partir da tabela 2, a seguir.

TABELA 2

Síntese dos papéis desempenhados pelos agentes verificados pela Operação Lava a Jato

\begin{tabular}{|l|l|l|}
\hline \multicolumn{1}{|c|}{ Agentes } & \multicolumn{1}{|c|}{ Fatos } & \multicolumn{1}{|c|}{ Reflexos } \\
\hline $\begin{array}{l}\text { Empresas de } \\
\text { serviços por } \\
\text { empreitadas } \\
\text { (Empreiteiras) }\end{array}$ & $\begin{array}{l}\text { Cartéis de empreiteiras com o } \\
\text { objetivo de simular concorrência } \\
\text { real, mas com acordos que } \\
\text { definiam os ganhadores das } \\
\text { licitações, preços dos ganhadores } \\
\text { e divisão de projetos de } \\
\text { infraestrutura entre as empresas. }\end{array}$ & $\begin{array}{l}\text { Sangria financeira nos cofres } \\
\text { públicos; Pagamento de obras pela } \\
\text { Petrobras com valores bem acima } \\
\text { dos reais. }\end{array}$ \\
\hline $\begin{array}{l}\text { Funcionários } \\
\text { da Petrobras } \\
\text { S.A. }\end{array}$ & $\begin{array}{l}\text { Cooptação de funcionários que } \\
\text { limitavam a participação de } \\
\text { empresas nas licitações, } \\
\text { priorizando grupos de empresas } \\
\text { que pertenciam ao cartel } \\
\text { montando para tal fim. }\end{array}$ & $\begin{array}{l}\text { Celebração de acordos irregulares, } \\
\text { aditivos e contratos com } \\
\text { sobrepreço, redução e/ou omissão } \\
\text { de etapas no processo de } \\
\text { contratação, fornecimento de } \\
\text { inside information. Sangria } \\
\text { financeira na Petrobras. }\end{array}$ \\
\hline Intermediários \\
$\begin{array}{l}\text { Financeiros } \\
\text { (Doleiros) }\end{array}$ & $\begin{array}{l}\text { Intermediação dos recursos } \\
\text { ilicitos, lavagem de dinheiro e } \\
\text { pagamento aos envolvidos. } \\
\text { Empreiteiras-Intermediários- } \\
\text { Beneficiários. }\end{array}$ & $\begin{array}{l}\text { Movimentação financeira em } \\
\text { espécie fora do Brasil; simulação } \\
\text { de contratos com empresas } \\
\text { ficticias; pagamento pelos } \\
\text { intermediários aos beneficiários } \\
\text { em espécie, transferência fora do } \\
\text { pais e/ou pagamento com ativos } \\
\text { fisicos. }\end{array}$ \\
\hline Politicos & $\begin{array}{l}\text { Indicação de gestores vinculados } \\
\text { a partidos politicos, para } \\
\text { ocuparem cargos na Petrobras, } \\
\text { cujo papel era gerenciaro } \\
\text { esquema de corrupção. }\end{array}$ & $\begin{array}{l}\text { Indicação da Diretoria de } \\
\text { Abastecimento (2004-2012); } \\
\text { Diretoria de Serviço (2003-2012); } \\
\text { Diretoria Internacional (2003- } \\
\text { 2008). Participação de operadores } \\
\text { financeiros em nome de partidos } \\
\text { politicos. }\end{array}$ \\
\hline
\end{tabular}

Fonte: elaborado pelo autor a partir de Brasil (2017d, p. 1).

De acordo com Brasil (2017d, p. 1):

Nesse esquema, que dura pelo menos dez anos, grandes empreiteiras organizadas em cartel pagava propina para altos executivos da estatal e outros agentes públicos. O valor da propina variava de $1 \%$ a $5 \%$ do montante total de contratos bilionários superfaturados. Esse suborno era distribuído por meio de operadores financeiros do esquema, incluindo doleiros investigados na primeira etapa. (Brasil, 2017d, p. 1)

Nesse sentido, ao analisar as normas brasileiras de auditoria e os trabalhos dos auditores externos diante dos reflexos da OLJ, cumpre ressaltar que não se pode atribuir aos auditores a responsabilidade por fraudes praticadas pelos gestores nas suas respectivas empresas. Aos auditores, que deve cumprir as normas nacionais e internacionais de contabilidade e de auditoria, compete o papel de assegurar que as informaçóes divulgadas pelas entidades sejam fidedignas e reflitam a situação patrimonial dessas organizações (Freitas \& Cruz, 2016). Contudo, é, no mínimo, contraditório defender que os trabalhos foram desenvolvidos obedecendo às normas vigentes de contabilidade e auditoria, conforme está previsto nas Normas de Auditoria (CFC, 2012) se, por outro lado, as empresas mesmo auditadas estavam ou estão envolvidas em escândalos de corrupção, que dentre as práticas ilícitas envolvem fraudes contábeis e financeiros, a exemplo do que foi observado no âmbito da Operação Lava Jato no Brasil.

Ao mesmo tempo em que, apresentar práticas de governanças corporativas compatíveis com aquelas exigidas pelo mercado, a exemplo das práticas do Instituto Brasileiro de Governança Corporativa (último lançamento em 2015) e as requeridas pela Brasil Bolsa Balcão (B3) ${ }^{2}$, para ingresso no mercado de ações brasileiro, sinaliza para o mercado a preocupação das organizações com as suas práticas e transparência corporativa, não há garantias de que as decisões e práticas de gestão estão isentas de fraudes e atos ilícitos da administração. Essa perspectiva pode ser vista nos esquemas de corrupção evidenciado pela OLJ, cujas empresas envolvidas apresentavam práticas modernas de governança corporativa, a exemplo da JBS, Petrobras, 
dentre outras, mas que não foram suficientes para mitigar os riscos de fraudes nessas empresas (Pereira $\&$ Souza, 2017).

Nos últimos anos, as Normas Brasileiras de Contabilidade e Auditoria vêm passando por um conjunto de mudanças e ajustes com o objetivo de se adequar às necessidades do mercado e acompanhar as mudanças ocorridas nas corporações ao longo dos anos. Em particular, essas mudanças buscam permitir um conjunto de técnicas que sejam suficientes para assegurar a integridade do patrimônio das entidades. Não obstante, cabe ressaltar que essa evolução não tem freado as constantes práticas de fraudes que se observam no mundo, em particular, no Brasil com a OLJ.

No âmbito do Conselho Federal de Contabilidade -CFC-, em consonância com as normas internacionais de contabilidade, um conjunto de normas vêm sendo editadas com o objetivo de disponibilizar aos profissionais de auditoria independente do Brasil substantivos insumos que ajudem no desenvolvimento dos trabalhos de forma robusta. As normas brasileiras de contabilidade técnicas de auditoria independente (NBC TA), com vigência desde 01 de janeiro de 2010, têm por objetivo orientar quanto aos procedimentos e finalidade do trabalho de auditoria, bem como, os campos de aplicações das normas, além dos profissionais a quem se destina, a exemplo de auditores externos e internos ou profissionais de contabilidade que não atuem como auditores (CFC, 2012).

Ao todo, o CFC editou 39 resoluções em 2009 (No 1.202 a 1.238/2009) cujas NBCs TA vão desde a Estrutura Conceitual, objeto da Resolução 1.202/2009 à NBC TA 810 que corresponde à Resolução No 1.238/2009 e aborda a responsabilidade do auditor na conformação e apresentação dos relatórios das demonstrações financeiras auditadas. Destaca-se, ainda, a NBC TA 315 / Resolução CFC No 1.212/2009 que enfatiza a necessidade do auditor identificar possíveis riscos de alterações das demonstrações financeiros, levando em consideração os aspectos organizacionais; a NBC TA 500 / Resolução CFC No 1.217/2009, a qual prevê que a auditoria deve considerar procedimentos e ações aderentes que subsidiem a identificação e qualificação de evidências suficientes e necessárias para a formular opiniões completas sobre o objeto; e a NBC TA 620 / Resolução CFC No 1.230/2009 salienta que o auditor pode utilizar trabalhos de especialistas de outras áreas para consubstanciar as suas conclusões. Assim, a norma aborda a responsabilidade do auditor em relação a esses especialistas, na obtenção de evidências que demandam o envolvimento de profissionais de área distinta da contabilidade e da auditoria (CFC, 2012).

Apesar de as NBCs TA, que são robustas, definirem as responsabilidades dos auditores quanto à identificação da existência de fraudes nas demonstrações financeiras, se faz necessária uma maior reflexão sobre sua efetividade. Assim, é preciso analisar se ao atender às normas, os auditores estão cumprindo, de fato, os seus papéis, pois o que vem sendo observado, nos últimos anos, é que, mesmo com as demonstrações contábeis atendendo às NBCa, conforme destacam Freitas e Cruz (2016), e os auditores, assim, estarem cumprindo o seu objetivo de acordo com as NBC TA, verifica-se que muitas das empresas que tiveram as suas demonstrações financeiras auditadas apresentaram práticas ilícitas, a exemplo daquelas evidenciadas pela OLJ.

Esse contexto requer a abertura da agenda de discussão sobre o papel do auditor e as estratégias para viabilizar a captura de práticas tais como as verificadas no âmbito da OLJ. Verifica-se que o papel atual da auditoria não se restringe à fiscalização de relatórios e documentos. Esse papel conforma-se por um conjunto de procedimentos, métodos e ferramentas que contribuam para a redução de riscos no processo de tomada de decisão, assegure a integridade do patrimônio corporativo, contribua para a implementação e manutenção de práticas de governança corporativa em linhas com os níveis exigidos pelo mercado e para o bom desempenho econômico-financeiro da organização (Biscalquim \& Vieira, 2015).

Ademais, faz-se necessária a diversificação das técnicas empregadas nos trabalhos dos auditores, que amplie os procedimentos de trabalhos previstos nas normas, através de uso de estratégias como a utilização de servidos de contadores forenses, uso de software de análise, mineração de dados, dentre outras estratégias, conforme destacam Bierstaker et al. (2006), Carneiro et al. (2017) e Nascimento et al. (2018). 
No que se refere aos termos mais presentes nos relatórios contábeis e de pareceres de auditoria associados à OLJ, os dados extraídos do software Nvivo, permitem conhecer algumas correlações que compõe a estratégia de divulgação, com destaque para crimes de Cartel e Lavagem de dinheiro, conforme tabela 3.

TABELA 3

Quantidade de referências encontradas nos Relatórios Fonte

\begin{tabular}{|c|c|c|c|c|c|c|}
\hline & & & & ós e \% de Cobe & rtura & \\
\hline Relatórios Fo & & Cartel & Corrupção & $\begin{array}{l}\text { Lavagem de } \\
\text { Dinheiro e }\end{array}$ & $\begin{array}{l}\text { Embaraço a } \\
\text { Investigaçăo }\end{array}$ & PNM \\
\hline & 2012 & & & & & 0,0835 \\
\hline & 2013 & & & & & \\
\hline & 2014 & 0,5385 & 0,0848 & 0,0848 & 0,0680 & \\
\hline DFP & 2015 & 0,3383 & 0,1185 & 0,0139 & 0,0592 & \\
\hline & 2016 & 0,2049 & & & 0,0528 & \\
\hline & 2017 & 0,1684 & & & 0,0434 & \\
\hline & 2012 & & & & & \\
\hline & 2013 & & & & & \\
\hline Fermo & 2014 & 0,0945 & & 0,0355 & 0,0268 & \\
\hline $\begin{array}{l}\text { de } \\
\text { Referência }\end{array}$ & 2015 & 0,0815 & & 0,0134 & 0,0134 & \\
\hline & 2016 & 0,0248 & 0,0082 & 0,0117 & 0,0117 & \\
\hline & 2017 & 0,0325 & & 0,0094 & 0,0094 & \\
\hline & 2012 & & & & & 4,3260 \\
\hline & 2013 & & & & & 2,4980 \\
\hline Relatório de & 2014 & & & & & 7,3177 \\
\hline Auditoria & 2015 & & & & & 4,0152 \\
\hline & 2016 & 0,3200 & & 0,8938 & & 1,0766 \\
\hline & 2017 & & & & & 1,6865 \\
\hline Total & & 1,8033 & 0,2114 & 1,0624 & 0,2848 & 21,0036 \\
\hline Legenda: & & & & & & \\
\hline Nós $=$ Termo & He busc & artios & & & & \\
\hline \% de cobertu & $\begin{array}{l}=\text { Quar } \\
\text { traç̃es }\end{array}$ & de term & encontradose & expressos em \% & & \\
\hline
\end{tabular}

Fonte: dados da pesquisa (2018).

Por meio da tabela 3, é possível observar a concentração do termo Cartel com prevalência nas referências utilizadas pela Petrobras nas DFP e no Formulário de Referência. Por outro lado, cabe destacar que o termo Cartel foi utilizado unicamente do relatório de auditoria de 2016, portanto, dois períodos após a deflagração da OLJ.

Já o termo "Parecer não Modificado", frequentemente utilizado em relatórios de auditoria (até por uma obrigação normativa NBCTA700 e 705), chama atenção por apresentar variações quanto ao volume na medida em que a OLJ foi deflagrada (Figura 3).

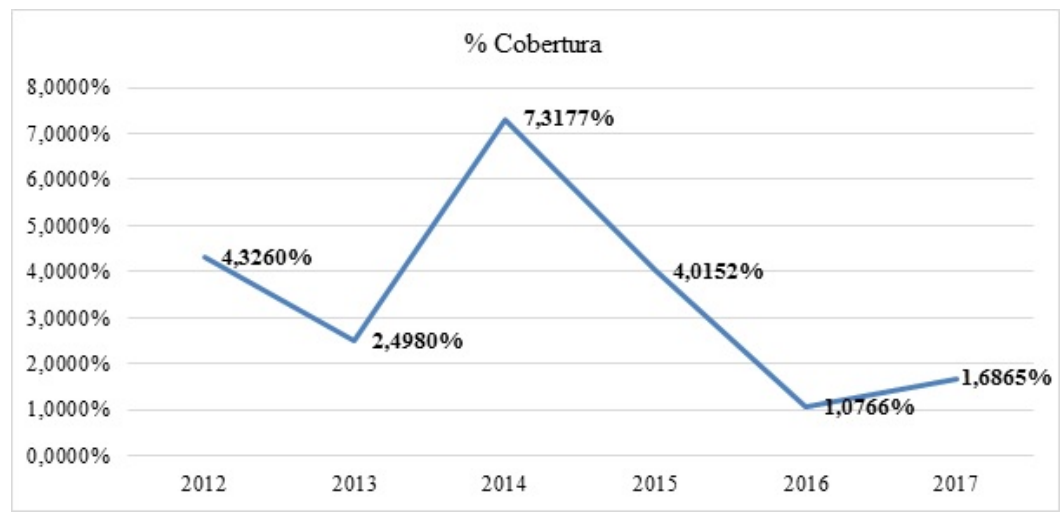

FIGURA 3

$\%$ de Cobertura do termo Parecer Não Modificado nos relatórios de auditoria Fonte: Dados da pesquisa (2018).

Esta perspectiva é um reflexo direto da OLJ nos pareceres de auditoria independente da Petrobrás no período, já que todos foram apresentados ao mercado com opinião não modificada dos auditores. Ressalta-se que esta modalidade de parecer é utilizada quando não são identificadas distorções relevantes (generalizadas ou não) no âmbito dos trabalhos de coletas de evidências por parte dos auditores independentes. Além disso, reforça-se que é facultado aos auditores utilizarem-se de parágrafos para mencionar assuntos de interesse dos 
usuários de acordo com o julgamento dos auditores independentes. Esse fato foi confirmado na medida em que revela aumento no ano de 2014.

No que se refere ao Figura 4 demonstra a correlação entre os Nós identificados no conjunto de relatórios do período em estudo. É possível perceber diferentes níveis de correlação dos Nós, variando de correlações positivas (aumentam conjuntamente) e correlações negativas (aumentam de modo inversamente proporcional). Essas correlações permitem a interpretação geral da associação dos termos utilizados pela Petrobras na medida em que evidencia informações em seus relatórios para o mercado.

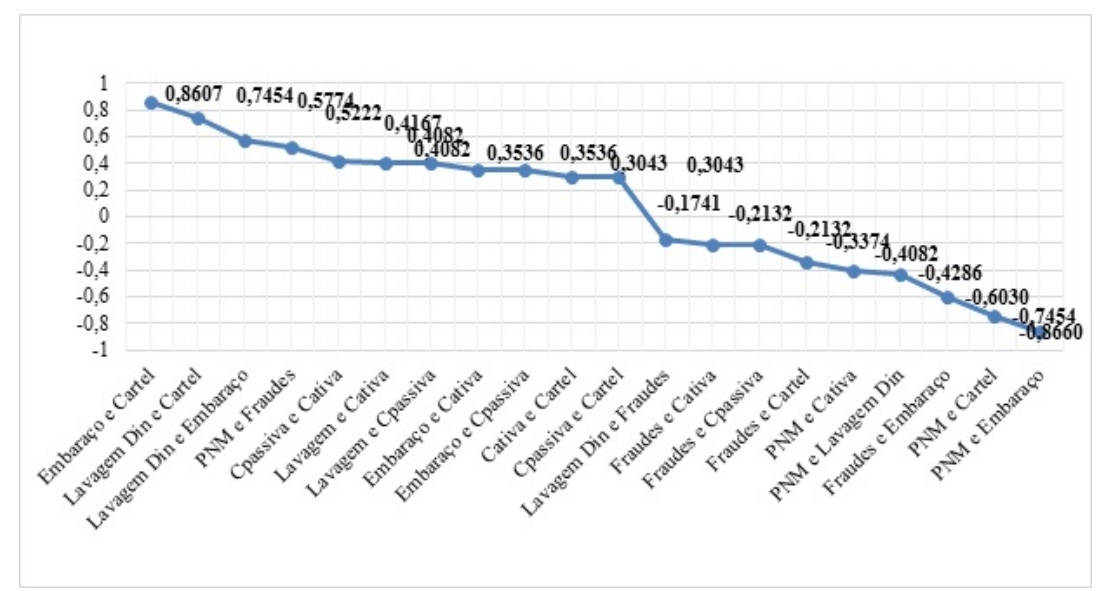

FIGURA 4

Coeficiente de correlação de Pearson entre os Nós identificados Fonte: Dados da pesquisa (2018).

A Correlação de Pearson calculada pelo software Nvivo permite analisar (entre os Nós) aqueles os quais estão citados em ambientes textuais semelhantes, permitindo entender associações nos quais os termos foram utilizados. Esta análise complementa os dados do \% de Cobertura, uma vez que adiciona o nível de correlação entre todos os Nós em todos os dados do período. Foram apresentados apenas os Nós que obtiveram nível de correlação de Pearson superior a zero, uma vez que o zero representa ausência completa de correlação.

Um dos destaques aparece para o Embaraço e Cartel, com correlação de 0,8607 (máxima de 1,0000). Apesar do Embaraço ter apresentado um baixo \% de Cobertura (Tabela 3), o índice demonstra que há alta correlação deste (Embaraço) com o termo Cartel. Isso demonstra a força da associação dos termos nos relatórios apresentados em análise. De modo oposto, o termo PNM apresenta alta correlação negativa $(-0,8660$, sendo máxima negativa de -1,000) com o termo Embaraço, demonstrando que nos relatórios estes termos pouco foram utilizados no mesmo âmbito textual, haja vista que pode ser entendido como uma contradição informar ao mercado um termo crime associado a um termo PNM no qual enseja regularidade com as normas e fidedignidade das demonstrações contábeis com a realidade na qual espelham.

Assim, pode-se verificar que os achados desta pesquisa, no que analisou apenas a Petrobras, corrobora os resultados evidenciados pela pesquisa de Schmitz e Rover (2017), que embora teve objetivo geral diferente do objetivo desta pesquisa, verificou por meio de pesquisa qualitativa (mediante verificação de atendimento ou não à questões relacionadas com Programa de Integridade) e quantitativo (através de teste de Mann-Whitney) evidenciou maior volume de evidenciação entre as empresas empreiteiras investigadas no âmbito da OLJ.

Ademais, observou-se ainda que os achados desta pesquisa corroboraram, também, com as pesquisa de Schmitz e Rover (2017), no que tange à manutenção da estratégia de legitimação observada nesta pesquisa em relação a Petrobras com relação as empresas investigadas estudadas em sua amostra. Desse modo, os resultados da pesquisa corroboram o que determina a teoria da legitimidade (Dias Filho, 2012; Hybels, 1995).

A Operação Lava Jato -OLJ-impactou significativamente o patrimônio e valor das diversas organizações, a exemplo da Petrobras. Pode-se observar que os mecanismos atuais de coleta e exame da fidedignidade de documentos e dados utilizados na composição do relatório e pareceres elaborados pelos auditores externos 
precisam ser mais bem estruturados e robustos, já que os utilizados na atualidade, na condução dos trabalhos que antecederam à OLJ, não foram suficientes para detectar práticas de fraudes e ilícitos das entidades auditadas e das que estiveram envolvidas no âmbito da OLJ, como foi o caso da Petrobras.

Conforme observa-se no âmbito das NBCs, TA, emitidas pelo Conselho Federal de Contabilidade CFC-, na execução dos trabalhos de auditorias, compete aos auditores externos levantarem documentos e informações necessárias acerca das demonstrações e registros contábeis e financeiros, podendo estes complementá-las com outros dados e informações. Tais documentos são cruciais na composição do parecer final que deve obedecer às premissas e aos objetivos dos trabalhos de auditoria.

Os fatos discutidos anteriormente levantam um debate sobre quais os limites dos trabalhos dos profissionais de auditoria externa. Sabe-se que todas as empresas envolvidas na OLJ receberam nos últimos anos avaliações de auditoria independente. Porém, até a deflagração da OLJ, os pareceres emitidos não evidenciaram, de forma contundente, os fatos que foram objeto da investigação conduzida pelo MPF e a Política Federal, limitandose a utilizar os termos apresentados neste trabalho, conforme Figura 2. Isso pode significar que o limite dos trabalhos dos auditores externos pode ser discutido de modo que possam obter ainda mais evidências e estas possam estar refletidas em seus relatórios.

Ainda que os trabalhos dos auditores avaliem os documentos e as demonstrações contábeis à luz das normas brasileiras e internacionais de contabilidade, a precisão na detecção das práticas de corrupção verificadas nas empresas brasileiras, é um fato a ser discutido e refletido quanto à necessidade da ampliação e/ou ajustes no papel do auditor independente. Quanto à gestão dos riscos envolvidos na execução dos trabalhos, o objetivo consiste em assegurar o patrimônio avaliado por meio da emissão de opinião independente.

\section{CONSIDERAÇÕES FINAIS}

A presente pesquisa objetivou analisar que reflexos a Operação Lava Jato -OLJ-pode gerar sobre os trabalhos desenvolvidos pela auditoria externa e suas normas no Brasil e quais os termos associados à OLJ mais presentes nos relatórios contábeis e pareceres de auditoria da Petrobras. Para o alcance do objetivo proposto realizouse a revisão de literatura, por meio da análise de trabalhos científicos, bem como análise documental, cuja abordagem da pesquisa foi qualitativa e descritiva, com uso de fontes de dados secundários, através de livros, artigos científicos, relatórios técnicos, normas e leis, bem como acesso a sites institucionais, relatórios financeiros e pareceres de auditoria, além de acesso a bases de dados públicas.

A partir dos resultados da pesquisa verificou-se que os principais reflexos da OLJ sobre os trabalhos desenvolvidos pelos auditores externos e sobre às NBCs TA, são da necessidade de mudanças tanto de natureza técnica e procedimental quanto de natureza legal e normativa.

No que se refere aos reflexos nos aspectos técnicos e procedimentais dos trabalhos dos auditores externos, observa-se a necessidade de mudanças e melhorias nos instrumentos atuais de coleta e exame da fidedignidade dos dados e documentos coletados durante os trabalhos, mediante o uso de tecnologias, que auxiliem no refinamento dos dados, a exemplo de softwares e ferramentas de big data que auxiliem na mineração de dados em face da grande quantidade de dados que precisam ser analisados e cruzados para a geração de informações às tomadas de decisões, gerando maior precisão na detecção de fraudes e práticas ilícitas nas organizações. Já no que se referem aos aspectos legais e normativos, os reflexos da OLJ evidenciaram fragilidades nas normas de auditorias atuais, que se mostraram limitadas diante das sofisticações nas práticas de fraudes, a exemplo daquelas evidenciadas a partir da OLJ, o que requer uma rediscussão e reformulação dos dispositivos normativos e orientadores dos trabalhos dos auditores externos.

A pesquisa evidenciou, também, que em relação aos termos observados nos relatórios contábeis e pareceres de auditoria, verificou-se uma maior concentração do termo Cartel nas Demonstrações Financeiras Padronizadas. No entanto, com relação ao relatório de auditoria, o referido termo apareceu, especificamente, 
no relatório do ano de 2016, ou seja, dois exercícios depois do início da OLJ. Conforme evidenciado nos resultados, o termo "Parecer não Modificado", utilizado quando não se observa divergências relevantes, apresentou variações quanto ao volume em face da deflagração da OLJ, o que evidencia que houve reflexos da OLJ nesse sentido.

Diante do exposto, verificou-se que tanto os órgãos responsáveis por emissão de normas brasileiras de contabilidade no Brasil, a exemplo do Conselho Federal de Contabilidade, quanto os profissionais da área precisam desenvolver e propor estratégias diversificadas na condução dos trabalhos dos auditores externos, que combinem conhecimentos, habilidades e metodologias avançadas de rastreamento de fraudes e práticas ilícitas nas organizações que permitam identificar, de forma mais precisa e tempestiva, fatos e atos que podem impactar, negativamente, os patrimônios corporativos. Além disso, é preciso que os trabalhos dos auditores externos sejam executados de forma articulados com órgãos governamentais, a exemplo da Receita Federal do Brasil e o Conselho de Controle de Atividades Financeiras, para assegurar conclusões consistentes e fidedignas.

Por fim, sugere-se, em investigações futuras, visando superar as limitações da presente pesquisa, a realização de uma pesquisa triangulando os achados da OLJ, com os dados evidenciados pelas empresas ex ante e expost à operação, seja nas demonstrações e relatórios financeiros das empresas, seja nos relatórios e pareceres das auditorias externas, a fim de analisar a possível mudança dos conteúdos dos documentos e procedimentos dada a ocorrência dos fatos levantados pela OLJ.

\section{Referências}

Agoglia, C., Beaudoin, C., \& Tsakumis, G. (2009). The effect of documentation structure and task-specific experience on auditors' ability to identify control weaknesses. Behavioral Research in Accounting, 21(1), 1-17. https://doi. org/10.2308/bria.2009.21.1.1

Almeida, M. (2017). Auditoria: um curso moderno e completo, 9ª ed. São Paulo: Ediotorial Atlas.

Biscalquim, A., \& Vieira, E. (2015). A auditoria interna como fortalecimento da governança corporativa nas empresas de capital aberto. REDECA, 2(2), 56-72. https://revistas.pucsp.br/redeca/article/view/28564

Bierstaker, J., Brody, R.., \& Pacini, C. (2006). Accountants' perceptions regarding fraud detection and prevention methods. Managerial AuditingJournal, 21(5), 520-535. https://doi.org/10.1108/02686900610667283

Brasil, Bolsa, Balcão - B3. (2017). B3: O resultado da combinação entre a BMß FBOVESPA e a CETIP. Disponível em: http://www.b3.com.br/pt_br/;. Acesso em: 21/11/2017.

Brasil. (2017a). Entenda o Caso. Ministério Público Federal (MPF). Disponível em: http://www.mpf.mp.br/para-o-c idadao/caso-lava-jato/entenda-o-caso. Acesso em: 27 de outubro de 2017.

Brasil. (2017b). MPF lança novo site com dados da Operação Lava Jato. Ministério Público Federal (MPF). Disponível em: http://www.mpf.mp.br/pgr/noticias-pgr/mpf-lanca-novo-site-com-dados-da-operacao-lava-jat o. Acesso em: 21/11/2017.

Brasil. (2017c). Caso Lava Jato. Ministério Público Federal (MPF). Disponível em: http://www.mpf.mp.br/para-o-c idadao/caso-lava-jato. Acesso em: 22/11/2017.

Brasil. (2017d). Ministério Público Federal (MPF). Entenda o Caso. Disponível em: http://www.mpf.mp.br/para-ocidadao/caso-lava-jato/entenda-o-caso. Acesso em 22/11/2017.

Brasil. (2017e). A Lava Jato em números no Paraná. Ministério Público Federal (MPF). Disponível em: http://www. mpf.mp.br/para-o-cidadao/caso-lava-jato/atuacao-na-1a-instancia/parana/resultado. Acesso em 22/11/2017.

Brasil. (2017f). Linha do Tempo. Ministério Público Federal (MPF). Disponível em: http://www.mpf.mp.br/para-ocidadao/caso-lava-jato/atuacao-na-1a-instancia/parana/linha-do-tempo. Acesso em 22/11/2017.

Buosi, M. E. d. S. (2014). Estudo de correlação e causalidade entre o desempenho financeiro e de eficiência no combate às emissões de gases de efeito estufa das empresas do mercado de capitais brasileiro. Dissertação Mestrado, 
Universidade de São Paulo, São Paulo, 2014. Disponível em: http://www.teses.usp.br/teses/disponiveis/12/12 139/tde-22012015-155305/publico/MariaEugeniadosSantosBuosiVC.pdf.

Carneiro, Y., Szuster, N., Siqueira, J., \& Fonseca, A. (2017). Contabilidade forense: a aplicação da atividade contábil investigativa e sua perspectiva futura no brasil. Revista de Contabilidade do Mestrado em Ciências Contábeis da UERJ, 21(3), 56-73. https://doi.org/10.12979/26273

Clarkson, M. B. (1995). A stakeholder framework for analyzing and evaluating corporate social performance. Academy of Management Review, 20(1), 92-117. https://doi.org/10.5465/amr.1995.9503271994

Conselho Federal de Contabilidade - CFC. (2012). Normas Brasileiras de Contabilidade: NBC TA - De Auditoria Independente: NBC TA estrutura conceitual, NBC TA 200 a 810. Brasília: CFC. Disponível em: http://portalc fc.org.br/wordpress/wp-content/uploads/2013/01/NBC_TA_AUDITORIA.pdf. Acesso em: 23/10/2017.

De Almeida, L., Vieira Neto, J., Abunahman, J., \& Nascimento, F. d. (2017). Um estudo documental sobre a Lei Dodd Frank: fraudes e aspectos contábeis. $R A G C, 5(19), 61-85$. http://www.fucamp.edu.br/editora/index.php/ragc /article/view/862

Dias Filho, J. M. (2012). A pesquisa qualitativa sob a perspectiva da teoria da legitimidade: uma alternativa para explicar e predizer políticas de evidenciação contábil. Interface - Revista do Centro de Ciências Sociais Aplicadas , .(1), 72-86. http://www.spell.org.br/documentos/ver/13370/a-pesquisa-qualitativa-sob-a-perspectivada-teoria-da-l egitimidade--uma-alternativa-para-explicar-e-predizer-politicas-de-evidenciacao-contabil

Donaldson, T., \& Preston, L. (1995). The stakeholder theory of the corporation: Concepts, evidence, and implications. The Academy of Management Review, 20(1), 65-91. https://www.jstor.org/stable/258887?seq=1\#metadata_in fo_tab_contents

Dordevic, M., \& Dukic, T. (2015). Contribution of internal audit in the fight against fraud. Economics and Organization, 12(4), 297-309. https://www.researchgate.net/publication/314260373_CONTRIBUTION_ OF_INTERNAL_AUDIT_IN_THE_FIGHT_AGAINST_FRAUD_t

Freeman, R. (2010). Strategic Management: A stakeholder Approach. New York: Cambridge University Press.

Freeman, R., \& Reed, D. (1983). Stockholders and Stakeholders: A new perspective on Corporate Governance. California Management Review, 25(3), 88-106. https://doi.org/10.2307/41165018.

Freeman, R. (2010). Strategic Management: A stakeholder Approach. New York: Cambridge University Press.

Freitas, C., \& Cruz, M. (2016). Riscos nos trabalhos de asseguração razoável: Um estudo aplicado ao nível de reporte nos relatórios de auditoria emitidos sobre as demonstrações contábeis de algumas empresas envolvidas na operação lava jato. Revista Eletrônica Gestão e Negócios, 7(1), 1-21. http://s3.uninove.br/app/uploads/2016 /12/08101619/1481210179-camila-pacheco.pdf

Hybels, R. (1995). On legitimacy, legitimation, and organizations. A critical review and integrative theoretical model. Academy of Management Proceedings, 1(1), 241-245. https://doi.org/10.5465/ambpp.1995.17536509.

Lélis, D. (2010). Percepção de auditores e auditados sobre as práticas de auditoria interna em uma empresa do setor energético. Dissertação de Mestrado. Universidade Federal de Minas Gerais.

Lima, K. de P., Souza, Q. da S., Facheti, T., Anjos, R., \& Francchin, V. (2016). A auditoria e a contabilidade como ferramenta de combate à corrupção no setor público. Revista Conexão Eletrônica, 13(1), 1-11. http://dvl.ccn.uf sc.br/9congresso/anais/9CCF/20190708194751.pdf

Mendes, J., \& Martins, V. (2014). Normas Internacionais de Auditoria no Brasil: Uma análise do Nível de entendimento das Normas do Relatório dos Auditores pelos Profissionais que atuam na área. Revista de Administração, 12(22), 67-85. http://revistas.fw.uri.br/index.php/revistadeadm

Nascimento, R., Santos, P. d.; Santiago, J., Araújo, B., Lima, F., \& Maciel, A. (2018). Mineração de dados na identificação de empresas irregulares quanto ao pagamento de impostos. Revista de Engenharia e Pesquisa Aplicada, 3(3), 122-132. https://doi.org/10.25286/repa.v3i3.932.

Parmar, B., Freeman, R., Harrison, J., Purnell, A., \& De Colle, S. (2010). Stakeholder Theory: The State of the Art. The Academy of Management Annals, 4(1), 403-445. https://doi.org/10.1080/19416520.2010.495581 
Pereira, M. d. S., \& Souza, A. d. (2017). Paradoxos entre governança corporativa e ocorrência de práticas de corrupção em empresas públicas: uma análise a luz da teoria da agência. Revista Formadores - vivências e estudos, 10(4), 5-25. http://www.seer-adventista.com.br/ojs/index.php/formadores/article/view/846

Piacentini, N. (2004). Evidenciação Contábil Voluntária. Uma análise da prática adotada por companhias abertas brasileiras. Dissertação de Mestrado. Universidade do Vale do Rio dos Sinos - UNISINOS.

Rossi, A., Silva, P., \& Lopes, R. (2016). O papel da auditoria interna para prevenção de fraudes nas empresas. Revista Executive On-Line, 1(1), 105-119. https://doi.org/10.1080/14783363.2016.1253465.

Schmitz, C., \& Rover, S. (2017). Nível de disclosure anticorrupção das maiores empreiteiras no Brasil: uma análise comparativa das empresas investigadas e não investigadas na operação Lava Jato. Anais do $15^{\circ}$. Encontro Catarinense de Estudantes de Ciências Contábeis, Florianópolis-SC, de 21 a 22 de agosto, pp. 1-20.

Souza, M. A., Cruz, A. P., Machado, D. G., \& Mendes, R. d. C. (2008). Evidenciação Voluntária de Informações Contábeis por Companhias Abertas do Sul Brasileiro. Revista Universo Contábil, 4(4), 39-56. http://dx.doi.or $\mathrm{g} / 10.18028 /$ rgfc.v4i3.720 .

Souza, A., Silva Junior, A., Andrade, J., \& Fernandes, M. (2018). Retorno das Ações e Sensibilidade ao Risco de Mercado das Empresas Participantes do Índice Carbono Eficiente (ICO2) da B3 S.A.: Um estudo comparativo. Revista Universo Contábil, 14(2), 30-60. https://doi.org/10.4270/ruc.2018210

Stuart, I. C. (2014). Serviços de auditoria e asseguração na prática. AMGH Editora.

Vilela, E, Grossi, J., Carvalho, L., \& Ribeiro, K. (2018). A Petrobras após os escândalos de corrupção da operação LavaJato: uma análise do valor da empresa até 2016. Revista de Gestão do Unilassalle, 7(3), 9-26. http://dx.doi.org/ 10.18316/desenv.v7i3.4664.

\section{Notas}

* $\quad$ Artigo de reflexão.

1 Circunstâncias do trabalho incluem os termos do trabalho, inclusive se ele se refere a trabalho de asseguração razoável ou limitada, as características do objeto do trabalho, os critérios a utilizar, as necessidades dos usuários previstos, as características relevantes e o ambiente da parte responsável, além de outros assuntos como eventos, operações, condições e práticas, que podem ter efeito significativo sobre o trabalho (CFC, 2012, p. 10).

2 Brasil Bolsa Balcão (B3) é resultado da combinação entre a Bolsa de Valores, Mercadorias e Futuro de São Paulo (BM\&FBOVESPA) e a Central de Custódia e Liquidação Financeira de Títulos Privados (CETIP), cuja junção ocorreu em março de 2017 (B3, 2017).

\section{Licencia Creative Commons CC BY 4.0}

Para citar este artigo: Souza, A. L. R., \& Faria, J. A. (2020). Reflexos da Operação Lava Jato no âmbito dos trabalhos desenvolvidos pela auditoria externa no Brasil. Cuadernos de Contabilidad, 21. https://doi.org/1 0.11144/Javeriana.cc21.rolj 